The International Conference : Cities' Identity Through Architecture and Arts (CITAA)

\title{
Artistic, Aesthetic and Edificial Works as Constant Elements of the Inconsistant Physical Character of a City
}

DOI: $10.21625 /$ archive.v1i1.105

Basem Fadel Sayed Mohamed 1

${ }^{1}$ Head of City Beautification Division at New Urban Communities Authority, PhD in Fine Arts

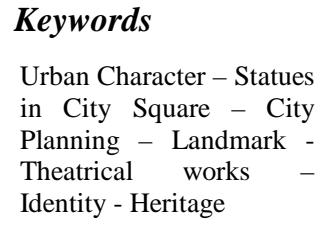

\begin{abstract}
Research Background:

Cities evolve and grow rapidly in a manner that is unprecedented throughout their long history. This great acceleration and growth is governed by many overlapping and intersecting factors (Economical, Social, Political, etc.), the process of identifying the city's character or identity is no longer an easy task. This appears more clearly in historic cities and historic areas that in most cases contrast with the civilizational, cultural and urban extension of the mother city. This therefore justifies the importance of polyphonic and edificial aesthetic works as they are elements of consistency and solidity of urbanism. Cities and their various components (facilities \& planning, objectives \& economics, construction \& architecture) have witnessed a new turn and were influenced by many factors. These factors and their results should therefore be identified in order to understand how they reflect on cities and how artistic and aesthetic works reflect on the form and identity of cities.
\end{abstract}

Research Objectives

The objectives of this research include identifying and studying the following:

- Developments in the urban growth of cities and how ithey affect these cities' identities.

- The relationship between architecture, artistic works and identity in the past and present.

- The effect of globalization and the technological evolution on both arts and architecture and their relationship.

- $\quad$ The extent to which people accept the message and form of aesthetic works.

- $\quad$ The nature of the relationship between the artist, the architect and the Architectonics throughout the urban beautification process.

This research postulates the following:

- The correlation between architecture, the city and the human being and his or her identity.

- $\quad$ The existence of changes in the form, characteristics and methods in today's cities.

This research addresses the form of the city throughout its development in the 20th century and the turn of the 21st century. It also addresses the historic roots of cities. 


\section{Research Methodology}

The emerging of cities has been one of the major landmarks of human history on earth as it reflects a significant evolution in all of the social, economic, administrative, political, religious and military fields. It even came before the concept of a state as we see in Egypt, Mesopotamia, China and even the Greeks who also started their civilization as a civilization of cities, before it took the form of a state or empire. [1]

This phenomenon also persisted -to a lesser extent- during the Middle Ages when cities were the centers of civilization, culture and even regimen during the different Islamic Caliphates [2] when Islamic cities scrambled amongst themselves. Every new succession that rose had to take a new capital for itself to be its title, front and seat. Each one also had to distinguish itself with a different architectural style.

European cities, however, faded and the characteristics of civilization and culture lapsed, at least when compared to cities of the Islamic east, with the exception of the movement of building massive cathedrals during that era. When the European Renaissance began in Italy, it was in fact a Renaissance of cities, since Italy didn't exist and wasn't as unified as we know it today. Perhaps this is what made Will Durant call these entities "City-States" in his significant work The Story of Civilization.

Cities remained rooted in society and history until they underwent the greatest change movement that accompanied the industrial revolution. That movement has not only changed the shape, concept and mission of cities, but also created another revolution in the demographic composition of cities and the world as a whole.

Almost the entireties of people of the world have been living on professions and crafts closely related to land and agriculture, so they lived in villages and areas beyond the gates of cities. However, since the industrial revolution and to this day, cities have been witnessing the largest migration from the countryside and other communities to the city in order to work in the factories or the other services that associated this new form and function of the city.

The tireless and ceaseless change of cities persists in parallel to the fascinating modern technology of electronics, cars, and communications. The appearance of modern construction materials and industries substantially impacted the form of cities. [3] Whether it is the shape, the proportions or the notion itself, all the aforementioned advancements necessarily had their impact on the city as a whole.

Nowadays, cities develop and grow rapidly to the extent that we can't keep up with their shifting and acceleration except through old photographs of them that capture those changes. Maps and aerial photographs are also ways to track the urban growth of cities over time.

The movement of our cities today is much like that of sand dunes in the desert, they may falsely appear still to the eye, but in reality they are ever changing. We were taught that there is no way to halt the movements of these sand dunes except through the implementation of entrenching elements. These elements are either structural or natural (seeding types of plants that clung to the soil to achieve land stabilization). The same concept is needed when dealing with the stabilization of the urban character of the city. If we can't stop the ever-changing character of a city, we can surely preserve its identity.

\section{Planning (Orientation and Integration)}

Controlling modern growth of the city through planning. To preserve a city’s identity, city planners must consider that the new areas that will be developed must be in harmony and in consistence with the existing planning and satisfies present and future needs. At every level of such planning, artistic, aesthetic and edificial works are taken into account so that the new urban growth comes as a real extension of the mother city visually, structurally and aesthetically. This should take place while bearing in mind that such works exist to solidify identity and the national, cultural and traditional character of a city and a whole nation.

Planning does not only include artistic works, but even possible urban projects (especially those carried out by the state, given its directive and sound decision making capabilities that may not be carried out by other parties especially under the pressure of economic inducements.) [4] A good example of this is Al-Hamidiyah Souq in the city of Abu Dhabi. Despite being a modern market complying with the highest standards of building, its modern design and even its name aligns with Arabian heritage. "Figure (1) (A\&B)"

\section{Old is Gold}

If cities, especially old ones, need re-planning to accommodate for the modern urban technological breakthrough, then under no circumstances should we demolish or marginalize the aesthetic, artistic, structural, antiquarian features of the city. However, city planners should rather subdue the planning in order to assimilate and aggrandize the role of such elements in confirming the identity and the physical character of the city. Similarly, in prestigious historic cities such as Rome, London and Paris "Figure 2 (A\&B)", these cities underwent modern planning, however, iconic monuments and areas remain and are being glorified in a way that harmonizes between history 
and modernity. The role of such elements is even emphasized in painting the profile of the city and its artistic, cultural and historic identity.

For a very long time, our Arab cities haven't been handled correctly. During which, many architectural and traditional icons of our cities' spirit were exhausted before we paid attention to modernization, identity and the physical character of the city while it was imperative that traditional and modern aspects remained in line with each other.

A simple comparison between the Triumphal arch in Paris "Figure2 (A\&B)" and Marcus Aurelius arch in Tripoli, Libya "Figure (3)" makes us realize our shortcomings in dealing with the heritage of our cities. Despite the latter being older, dating back to the Roman era, it has been sidelined and is not included in the traditional, artistic and aesthetic fabric of the city as much as it should have been.

\section{Centers of Gravity}

It is necessary to pay strong attention to the artistic, aesthetic work within modern planning of the city which represents artistic, visual and moral centers of gravity. Those works influence the shape and character of the city. The compelling examples are many: both The Eiffel tower and The Statue of Liberty in The U.S and the statue of Christ in Rio de Janeiro in Brazil. All of them are distinctive marks and icons for these cities artistically, in the media and even when it comes to tourism. The statue of Christ in Brazil "Figure 4" attracts 8.1 Million tourists alone, which is less than the number of tourists visiting the Eiffel tower or the statue of liberty.

In the Arab world, there are several iconic monuments and areas that need to be taken care of properly so that they can be considered within any new planning processes that will be implemented. Works such as the statue of Nahdet Masr, "Figure 5" the freedom monument in Iraq "Figure 6" and many others. The aforementioned are examples of what these icons represent by their role in the modulation of visual, cultural and physical character of the city, despite the small size and the spaces they occupy compared to the huge composition of the Arab city.

\section{Cities Memory}

There are certain artistic areas or objects that have cultural and national importance given their contributions to the urban fabric of the city. These artistic works shape a part of the nation's memory and a record of its pride, glory and history as they send lasting signals to every passerby, which is something no media outlet can accomplish. There are many examples like this such as memorials for martyrs "Figure 7" victories, statues of leaders, writers and national symbols in every field "Figure 8".

Some iconic symbols of a nation represent a certain era or regime and by time become part of the nation's urban fabric, however, in some cases they are destroyed to represent the end of that particular time period. An example of this is the statue of Saddam Hussein which was destroyed as a way to mark the end of his era and the fall of the regime, but the real symbol here was manifested in the fact that the statue was destroyed by the US army and the American flag replaced this statue, a colonizing sign no eye can miss "Figure 9".

This is what happened to many works for nothing other than its symbolic value. The evidence for this is that while many artistic works which are related to Saddam's era were destroyed, regardless of whether we agree with his policies or not, except for the freedom monument for the pioneering Iraqi artist Jawad Salim [5] "Figure6" that remained untouched although it is in the liberation square, in the center of protests and revolutionary events. This is because the public sensed that this artistic work represents their home country, far from any false directions.

This confirms Salim's wisdom as an artist, as when the president put him in charge of the mural and told him to create a portrait of the president, Salim created art that could be perceived as a national symbol that goes beyond any person or leader. That's why he abstained from putting this request into action, and his rejection of the request is the reason for the survival of his mural and prevention of its destruction.

\section{The Craft of Beauty}

It is important to encourage and celebrate all the artistic works and endeavors of the Arab world to bring up a generation that cares and values such works as well as cherish them. This would reflect on the shape, role, importance, and the reaction of those works to our cities, citizens and identities. It is also important to create works that are inspired by our heritage and are made by the hands of well-chosen artists like Mohammed Ghany Hekmat, as their work expresses hope, ambitions and issues in our home countries "Figure 11." Other examples appear through the works of the pioneer artist Mahmoud Mukhtar "Figure 5".

If we browse all the famous sculptors, foreigners of Arabs, we could see that the most famous of them are those who are most attached to societal issues within their countries. This attachment cannot be achieved except by local artists, as displaying foreign art can sometimes be unsuitable or lacking the understanding of the taste, culture or heritage of the country. This can be noticed in the city of Jeddah's cornice after the implementation of a new 
ambitious plan when non-Saudi and even non-Arab artists were invited, which resulted in works that do not reflect the Saudi Arabian culture. This made them victims of criticism and even sarcasm, "Figure 12" so much so that many works were removed under public pressure. We even find the statue of "The fist" by international artist César "Figure 13" removed and resold for no reason other than the lack of acceptance by the public. [6]

Many artworks in our Arab cities are exposed to many manifestations of negligence and marginalization but also wrong restoration. At this point, artists in the Arab world who are trained technically, culturally, and artistically to handle aesthetic works should come together and form a vision and a new orientation for Arab countries. Other cadres of artists affiliated with the local administrations of cities, trained on constant artistic restoration of works of art should also come together and do the same.
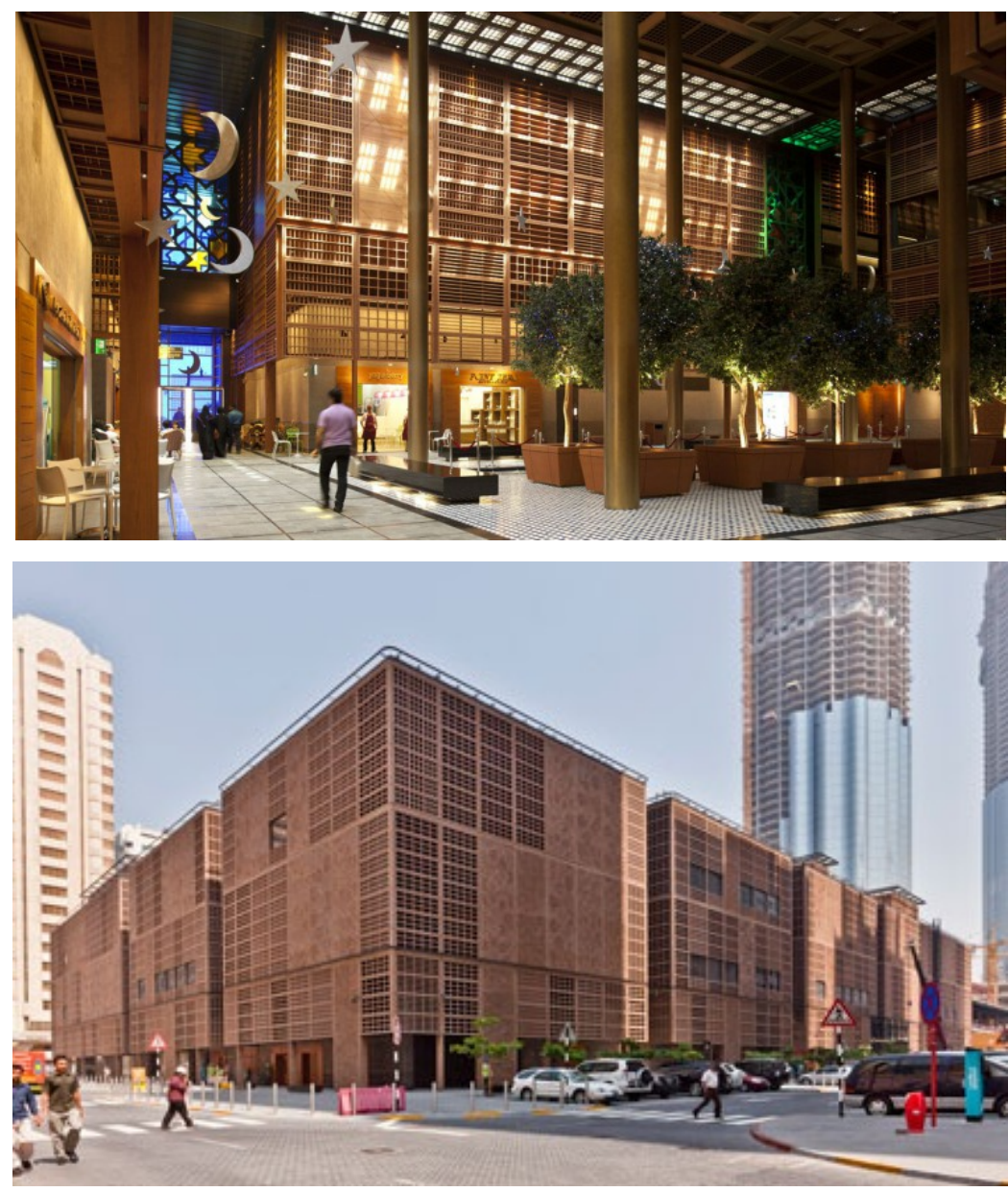

Figure1 (A\&B): Central Market (Al-Hamediya) in Abu Dhabi completed in 2014. Traditional Arabic elements were used to give an artistic, historic and cultural fragrant that affirms the city's identity.
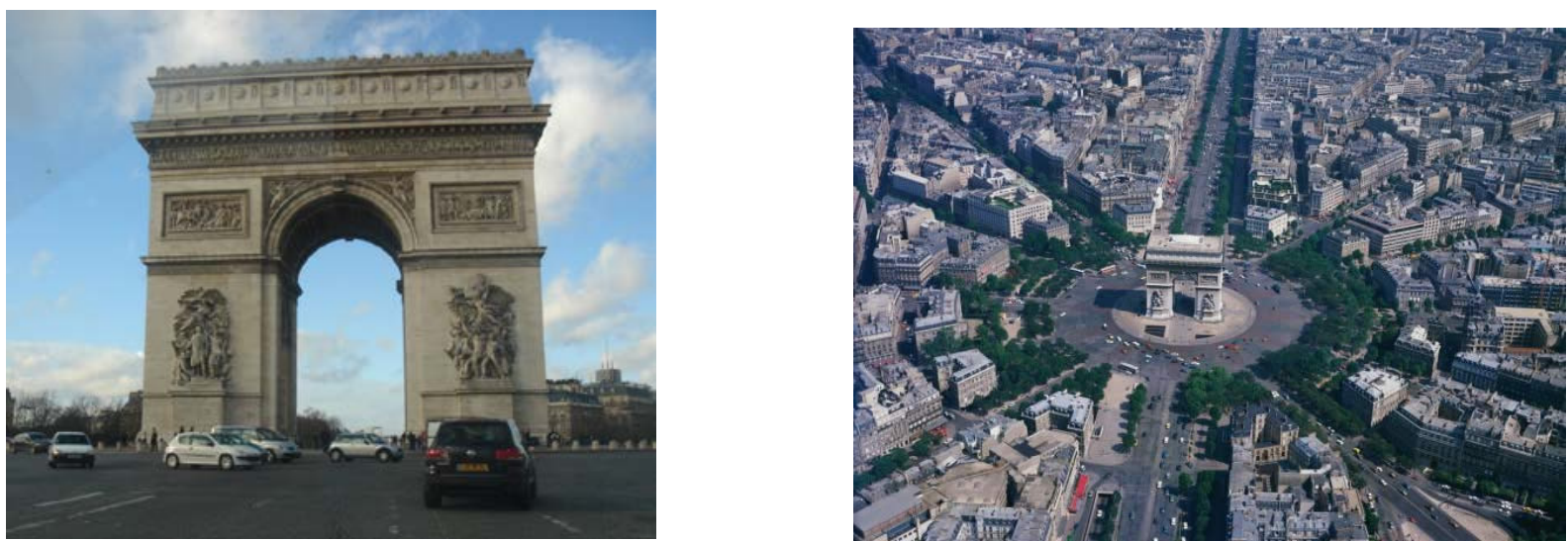
Figure2A: In 1836 The Triumphal arch in Paris was inaugurated. The design is by: Chalgrin and Raymond. Sculptor: François Rude
Figure 2B: Observe the level of attention paid to how the site of the arch is preserved and emphasized for its role in affirming the city's identity and as an aesthetic fulcrum.

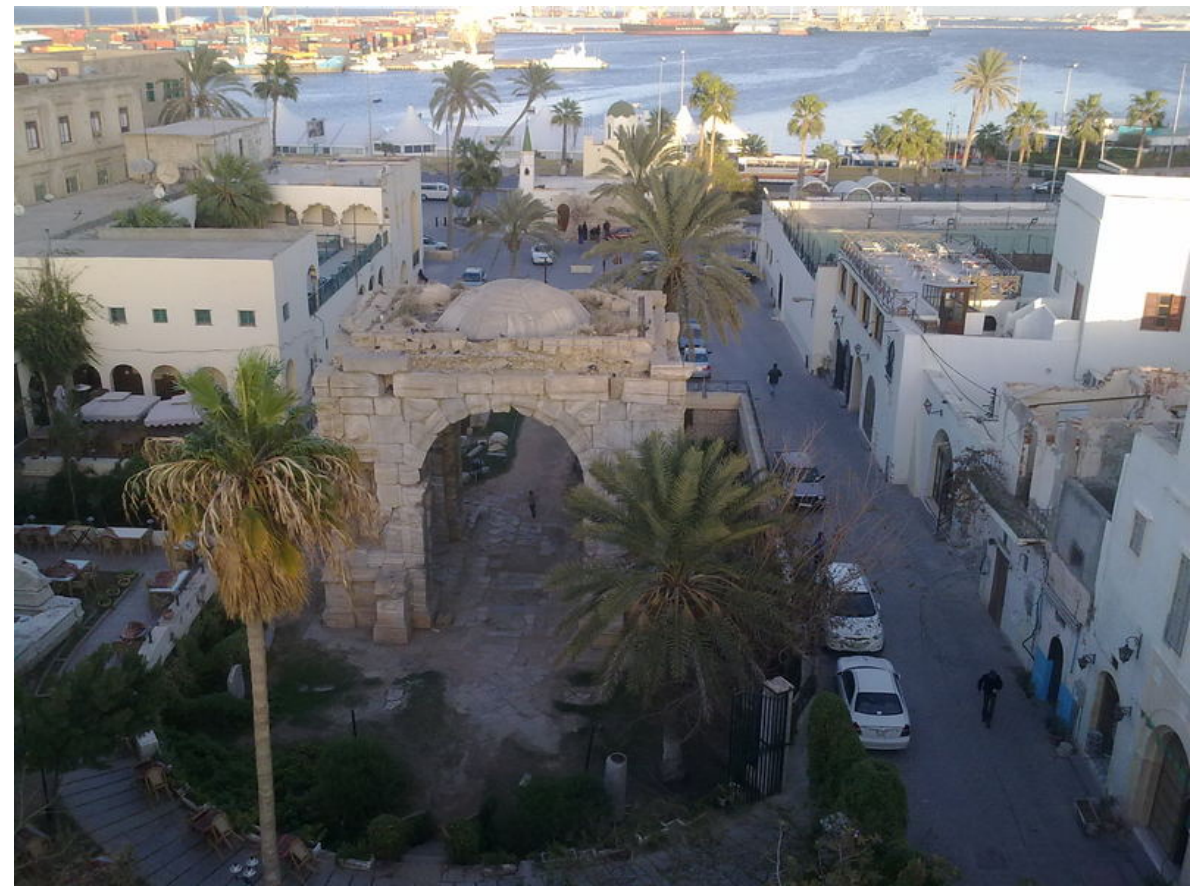

Figure3: Marcus Aurelius arch in Tripoli, Libya built in the year 165. Observe the inefficient planning and how the monument is surrounded by structures. Completely un-centered in the planning process. 


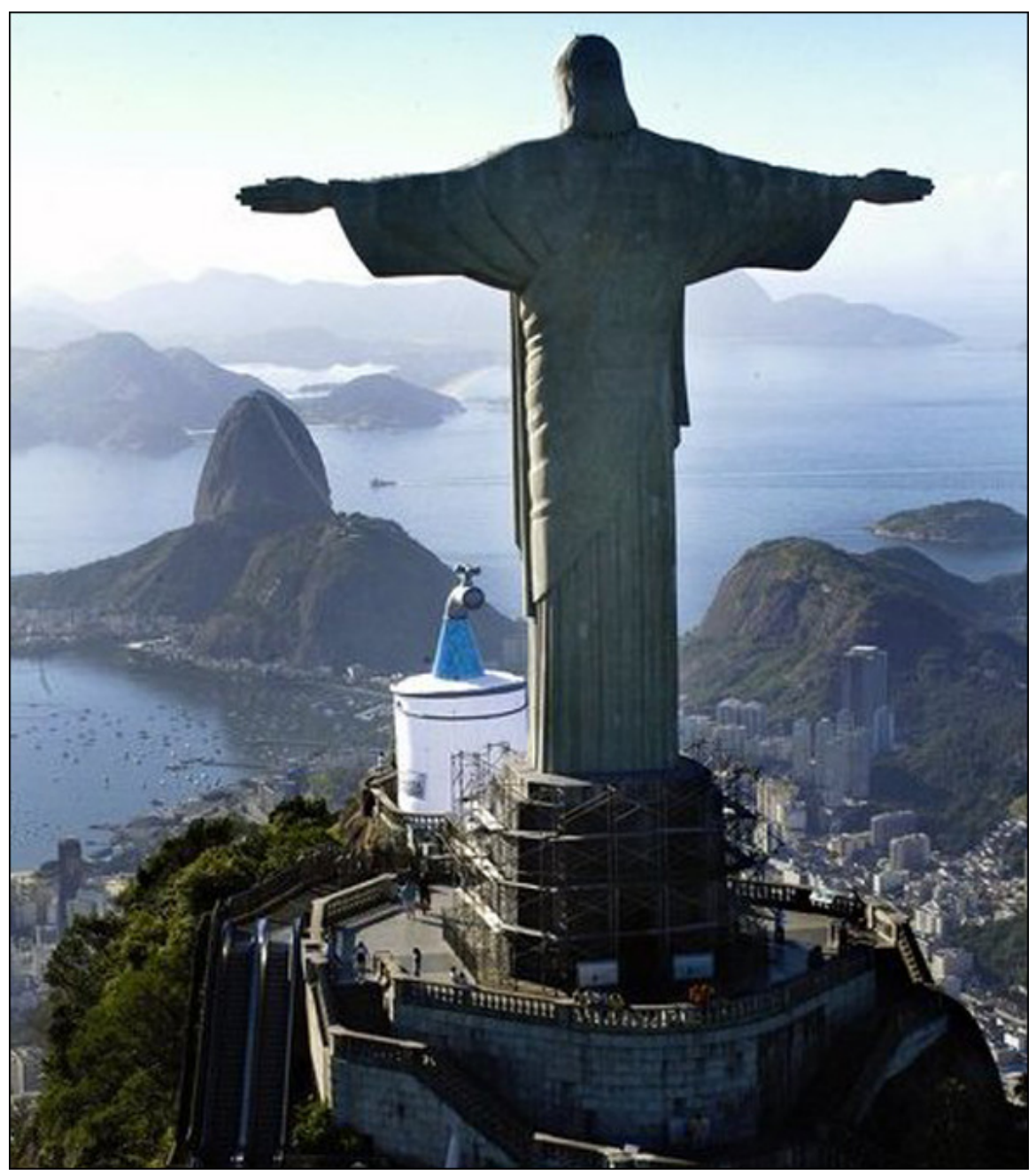

Figure4: Concrete-cast statue of Christ the redeemer in Rio De Janeiro, Brazil. Completed in 1931 and is considered one of the most important features of the city. Rising at 32 meters. Designed by Heitor da Silva Costa. In the style of Art Deco. created by French sculptor Paul Landowski. 


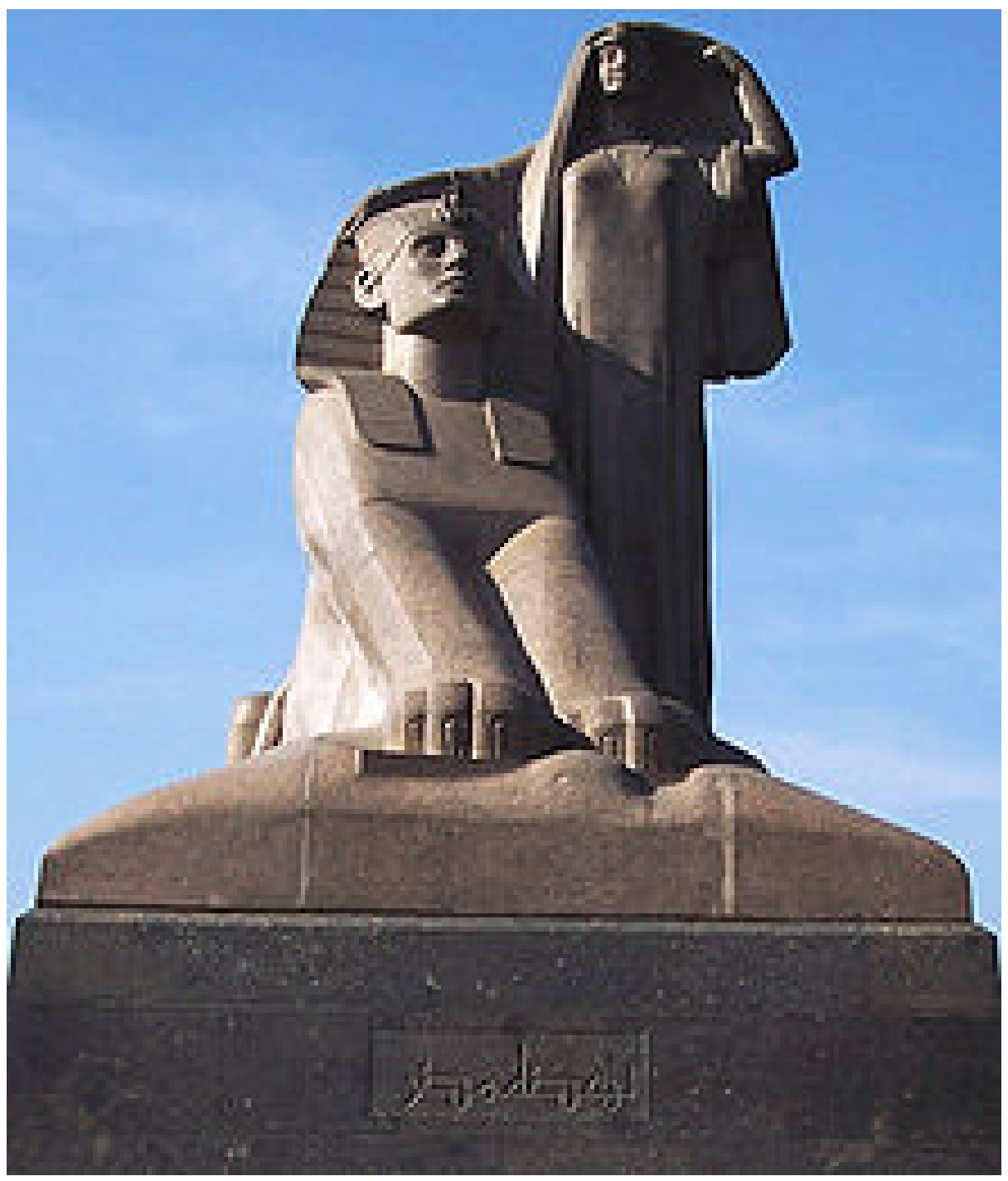

Figure5: Granite-cast statue of Nahdet Masr (Egypt's Reissuance) in Greater Cairo by sculptor Mokhtar. Completed in 1928. The first Arab sculpture by an Arab artist in the modern age. Looking to the future that's built on a glorious past is represented in this work

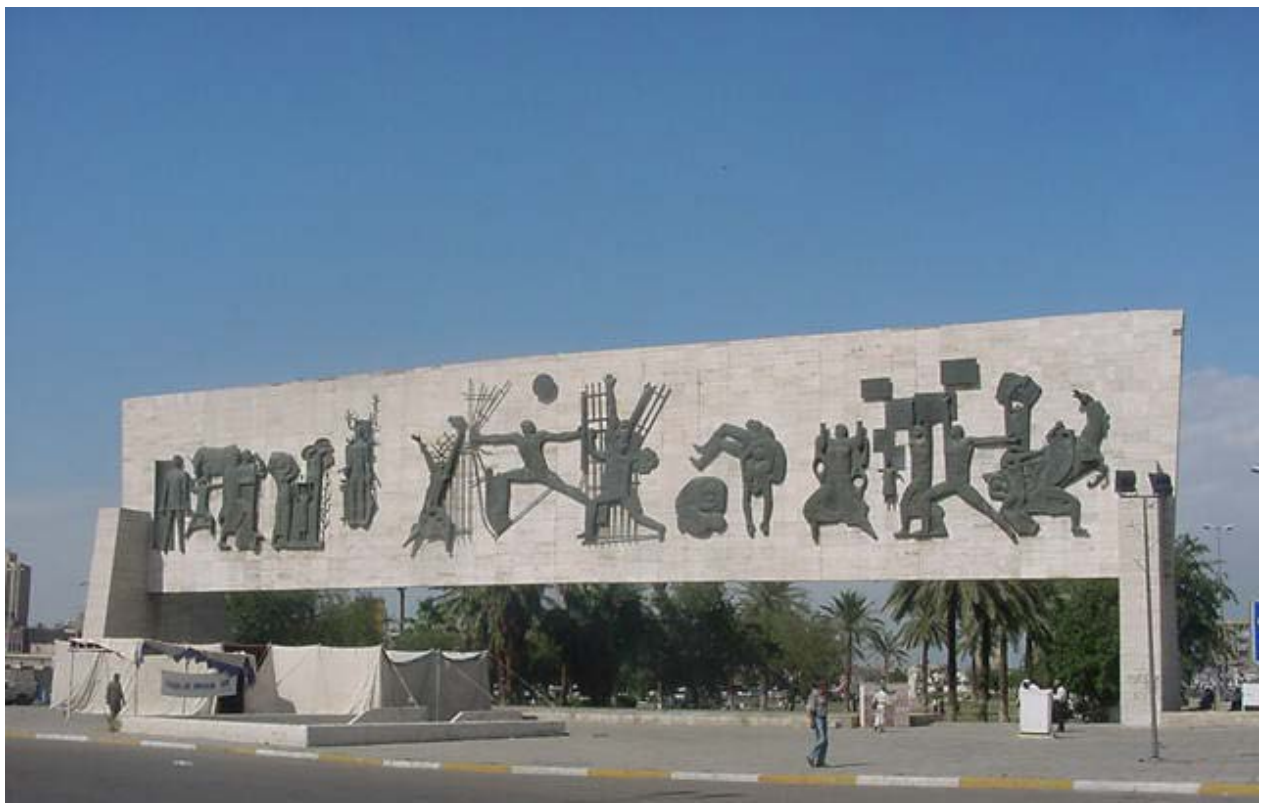

Figure6: Monument of Liberty by Iraqi artist Jawad Salim in Baghdad completed in 1961. This work is considered a symbol of modern Iraq with all its pains and hopes. The fact that it was not destroyed or taken off and sold for bronze like in many other works confirms the importance of the national role of such works being a part of Iraqis' sentiment and history. 


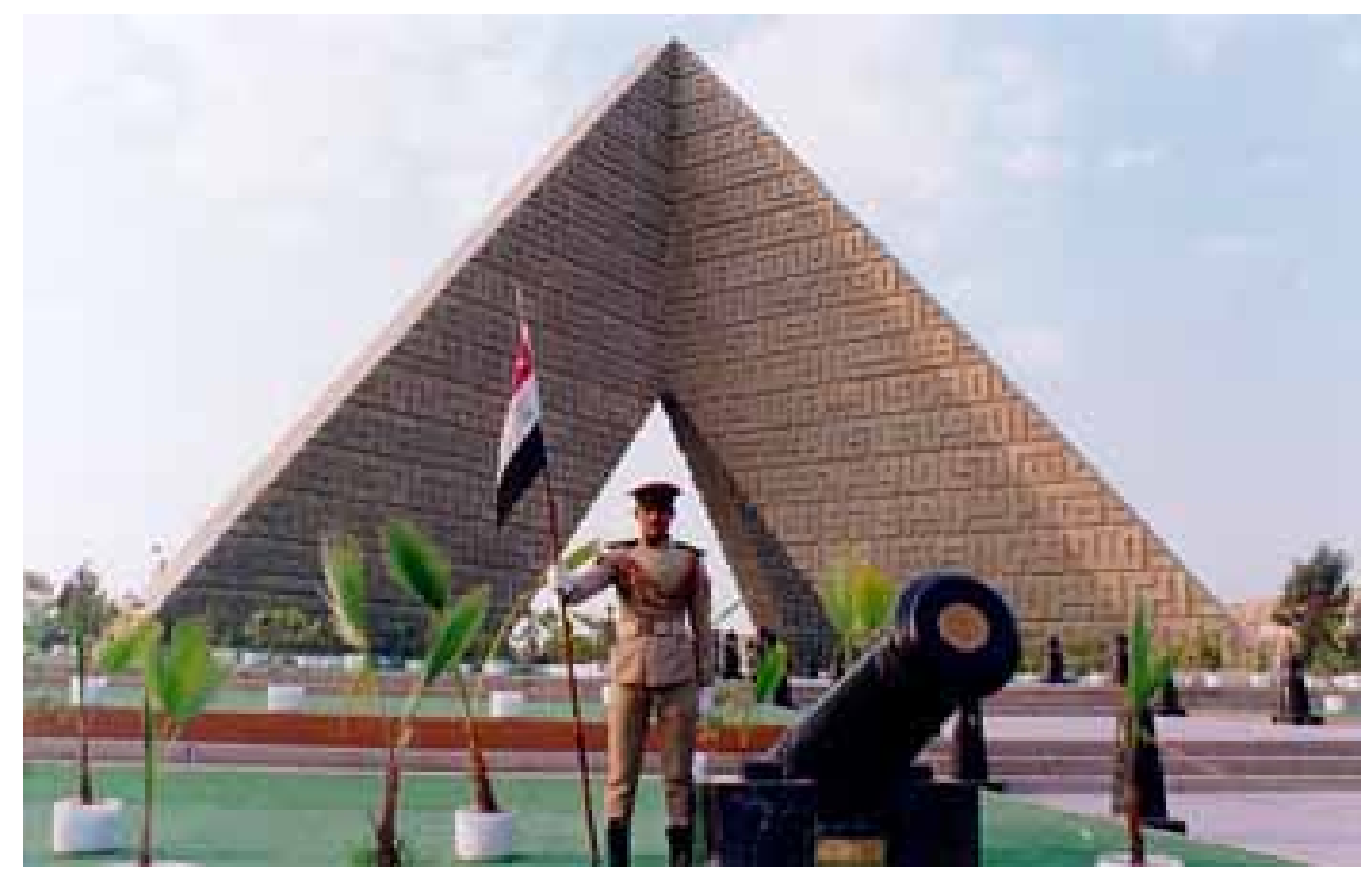

Figure7: unknown Soldier memorial in Cairo. Made of concrete and opened in 1975. Designed by Dr. Sami Rafe'. In the style of that of the ancient Egyptian Pyramids, while we can see the sides baring symbolic names of martyrs in Kofi Islamic calligraphy.

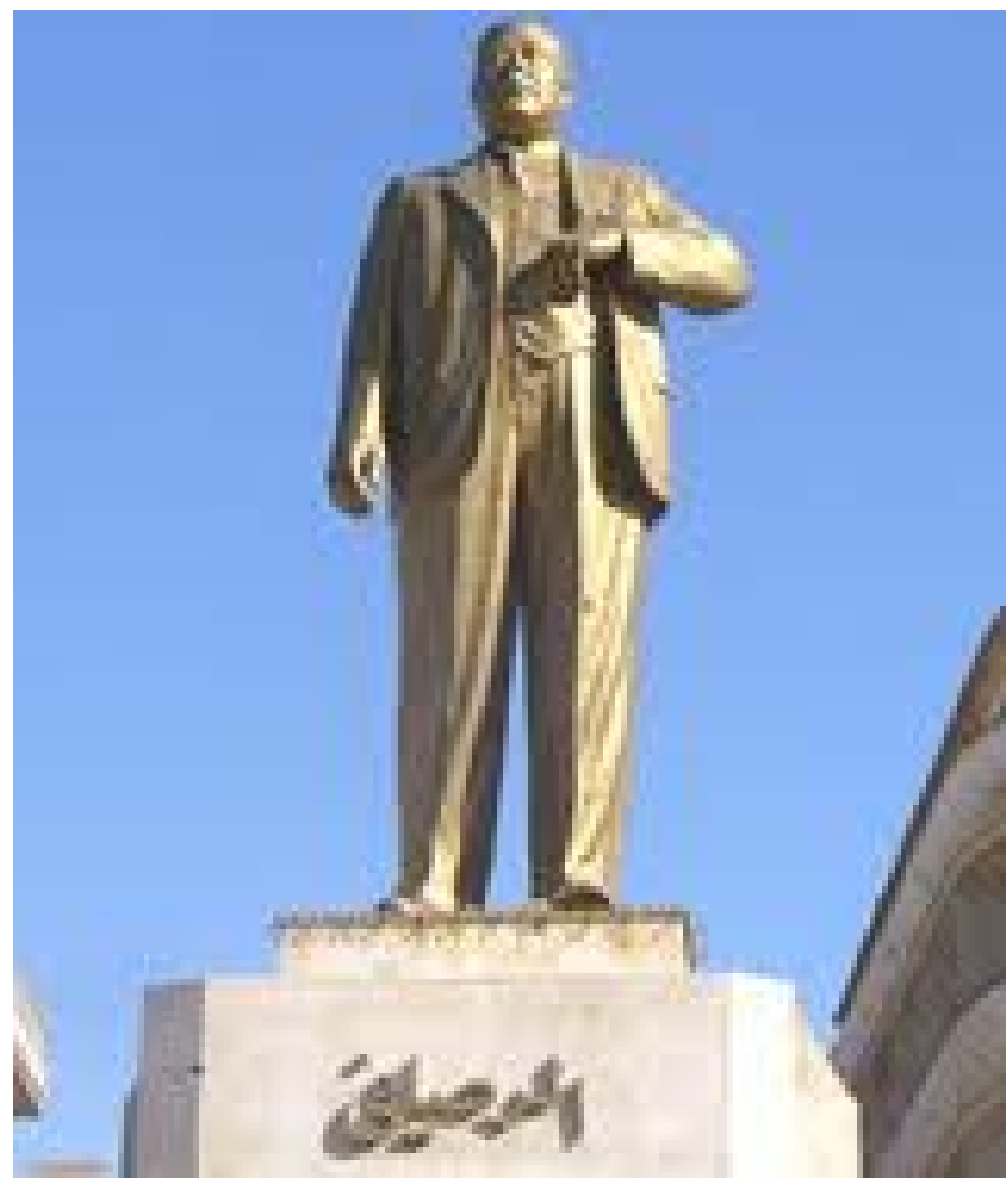

Figure8: bronze-cast statue of Iraqi poet Maarouf al Rusafi in Baghdad by sculptor Ismaiel Fattah Et-Turk in 1970. An example of that can be played by artistic works in perpetuating national icons in every field as symbols of homeland's memory. 


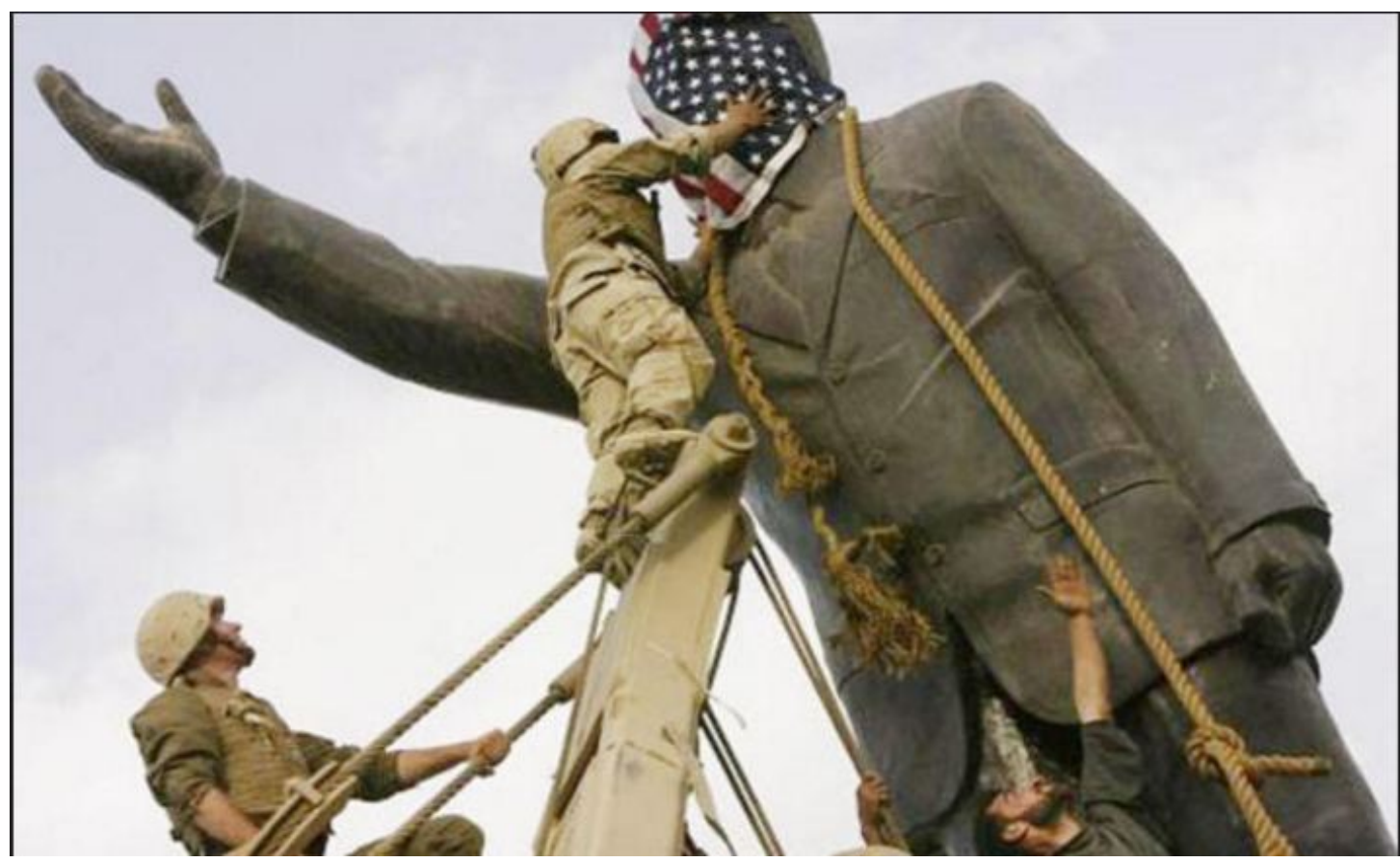

Figure9: The destruction of Iraqi president Saddam Hussien's statue following the invasion of Baghdad. The incident is considered an end of an era and the beginning of a new one.

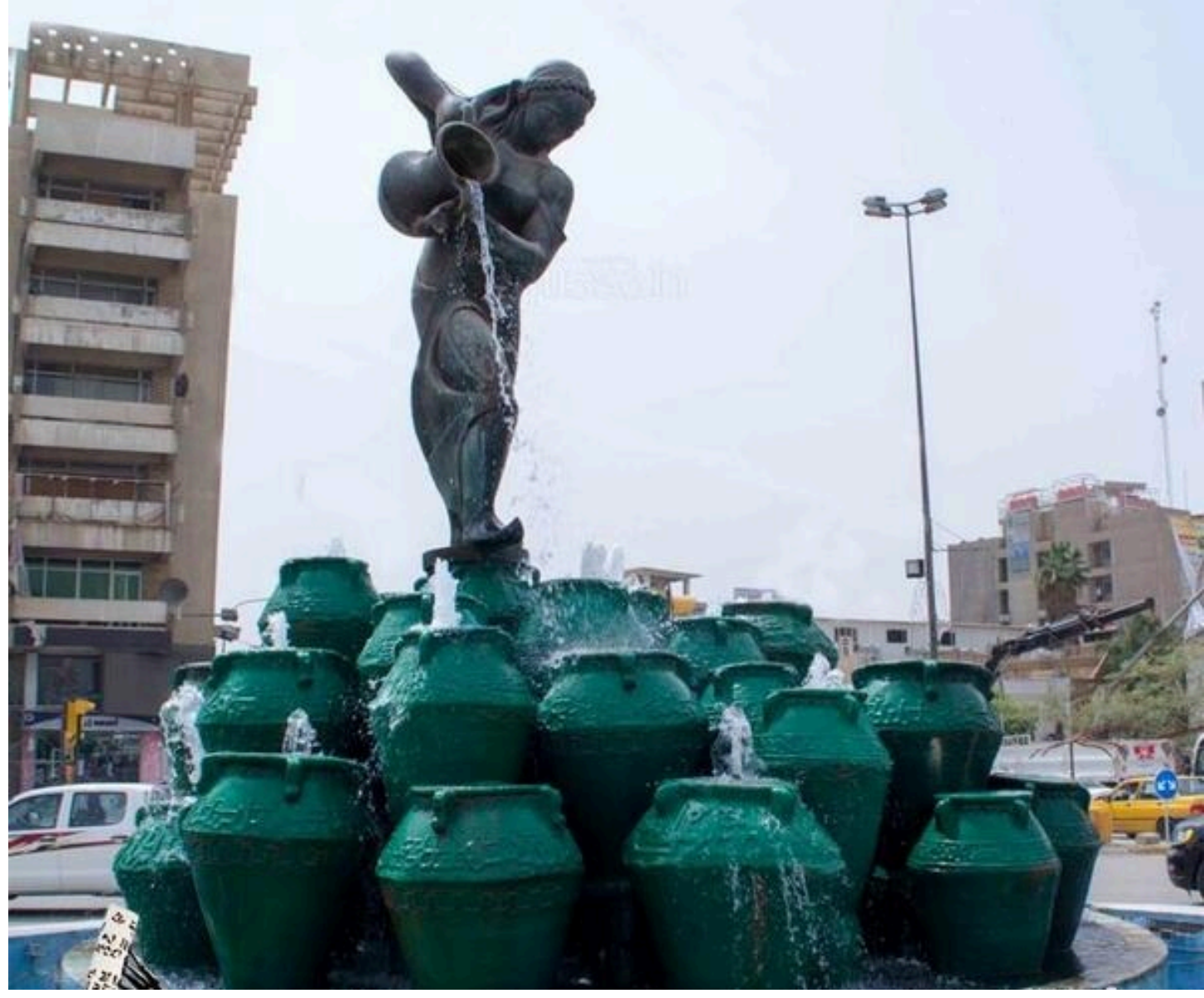

Figure10: The stature of Kahramana in Baghdad, by artist Mohammed Ghani Hekmat. It is inspired by tales from of Iraqi tradition. It's considered one of the city's icons. 


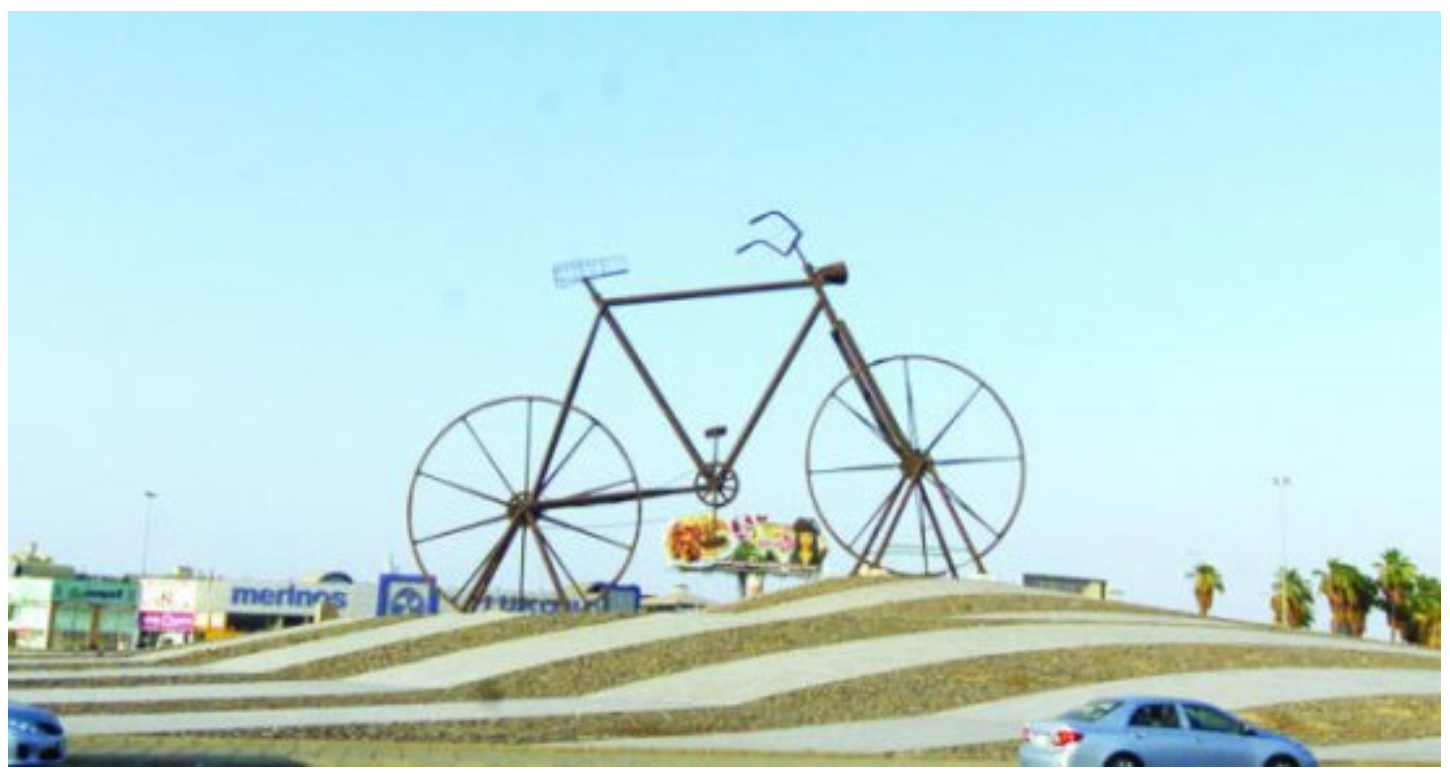

Figure11: The Bicycle statue. An international work implemented in the City of Jeddah

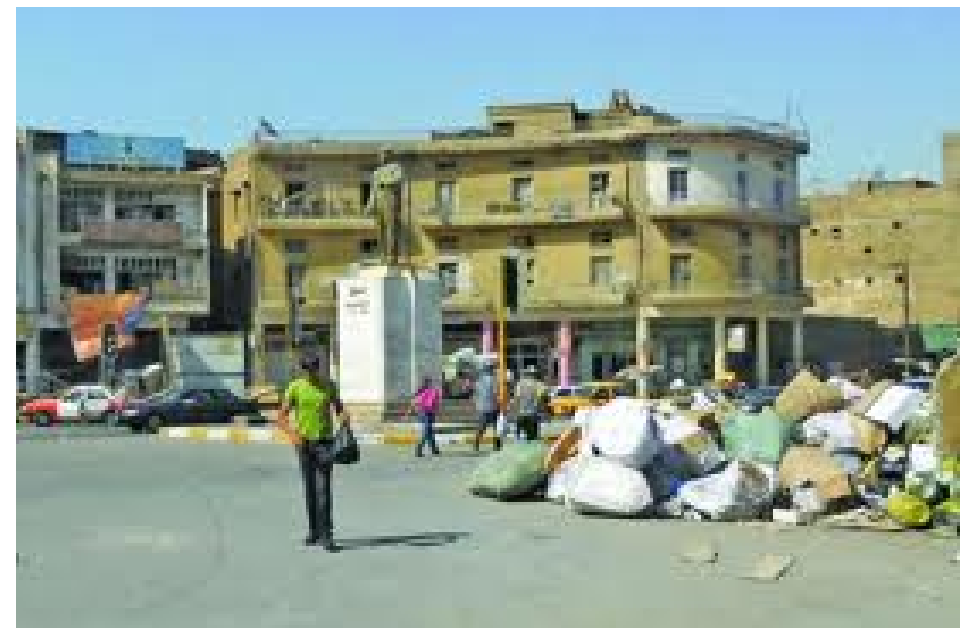

Figure12: Shameful image of what sometimes happens to works of art in our Arab world -despite their importance- of negligence and the absence of awareness. Despite the importance of the statue's position being in the forefront of the square, it did not prevent the piles of garbage to be tossed next to it.

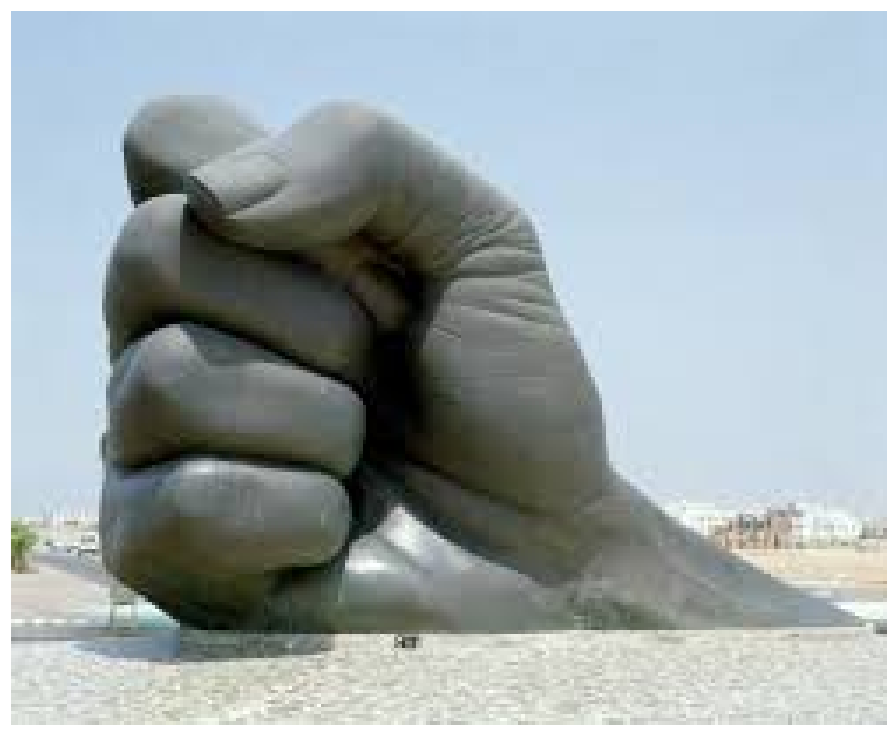

Figure13: This monumental bronze-cast sculptured in 1986 by César, known locally as "The Fist of Sultan" (or simply "The Fist"). 


\section{References}

1. Amira Matar-The scince of beauty and philosophy of art (Cairo: Gharib printing house. T3, 1998) Page 117.

2. Bassem Fadel: The Effects of Modernization and Technological Development on the Relationship between Relief Sculpting and Architecture in the Twentieth Century. Ph.D thesis-Faculty of Fine Arts in Cairo-2004) Page310.

3. Details: History of the Emergence of Cities and Civilizations.

4. History of the World: by a number of authors. Collected by Sir John A. Hammerton. Chapter1 Pages $433-460$ \& Chapter2 Pages 418 427. (In the translated Arabic version) by The Ministry of Public Knowledge (Cairo: En-Nahada El-Masriya Library).

5. Jabra Ibrahim Jabra: Jawad Saleem and The Freedom monument (Baghdad: Ministry of Information, 1972) Pages 15-38.

6. Please refer to the following sites to understand the public stance towards these works:

7. Sa'd Zaghlool Abdulhameed: Arts and Architecture in the State of Islam. (Alexandria: Knowledge Institution) Passim.

8. http://www.kalamon.org/articles-details-245

9. https://goo.gl/fz42lI

10. https://goo.gl/i06nrm

11. https://www.alaraby.co.uk/culture/2690e2f1-3d2e-488c-9ba0-e4db2c71e3c6 